\title{
Emasculation and Cross-Pollination Techniques for Tephrosia vogelii
}

\author{
D. K. Barnes ${ }^{1}$
}

\section{INTRODUCTION}

Teprosia vogelii Hook f., a tropical legume, is native to central Africa and South America. It has been used as a source of rotenoids for killing fish, a forage crop and as a shade plant for young coffee and tea plants. A breeding program was initiated at the U. S. Federal Experiment Station, Mayagüez, P.R., after Irvine and Freyre $(1)^{2}$ reported differences in total rotenoid content among introductions of $T$. vogelii. The primary objective of the program has been to increase the rotenone content in the leaves and stems. Significant progress in increasing the rotenoid content was reported by Barnes et al. (2). It is contemplated that T. vogelii could become a domestic source of rotenone for both the continental United States and Puerto Rico.

Most leguminous forage plants grown in temperate areas, such as alfalfa, birdsfoot trefoil and the perennial clovers, are primarily cross-pollinated crops that require insect pollinators. $T$. vogelii is unique because it is a selfpollinated species usually requiring insect pollinators to manipulate the flowers so self-pollination can take place.

Numerous honey bees (Apis mellifera) usually can be observed collecting nectar from $T$. vogelii flowers. However, their visits rarely result in pollination. A larger insect is needed to self-pollinate the large florets. The only large insect pollinator seen working the crop in Puerto Rico is the carpenter bee (Xylocopa brasilianorum L.). A size comparison of the honey bee and the carpenter bee on $T$. vogelii florets is presented in figure 1 . Note how the carpenter bee grasps the floral keel during the time it is gathering nectar from the flower. This action forces the stigma upwards, often rupturing the stigmatic membrane and bringing the dehisced anthers in contact with the stigma. Although the carpenter bee may move the style, only rarely is the stigma forced out of the floral keel petals. The author has not seen the stigma touch the abdominal portions of a bee and only rarely were bees seen with pollen on the underside of their bodies. Other evidence indicating that self-pollination is the general rule in $T$. vogelii is that the progeny

1 Federal Experiment Station, Crops Research Division, Agricultural Research Service, United States Department of Agriculture, Mayagüez, Puerto Rico. Present address: ARS, USDA, State Agricultural Experiment Station, Univ. Minn., St. Paul, Minn.

Italic numbers in parentheses refer to Literature Cited, p. 175. 
from open-pollinated seed on recessive white-flowered strains grown in the midst of dominant purple-flowered strains are almost exclusively white flowered.

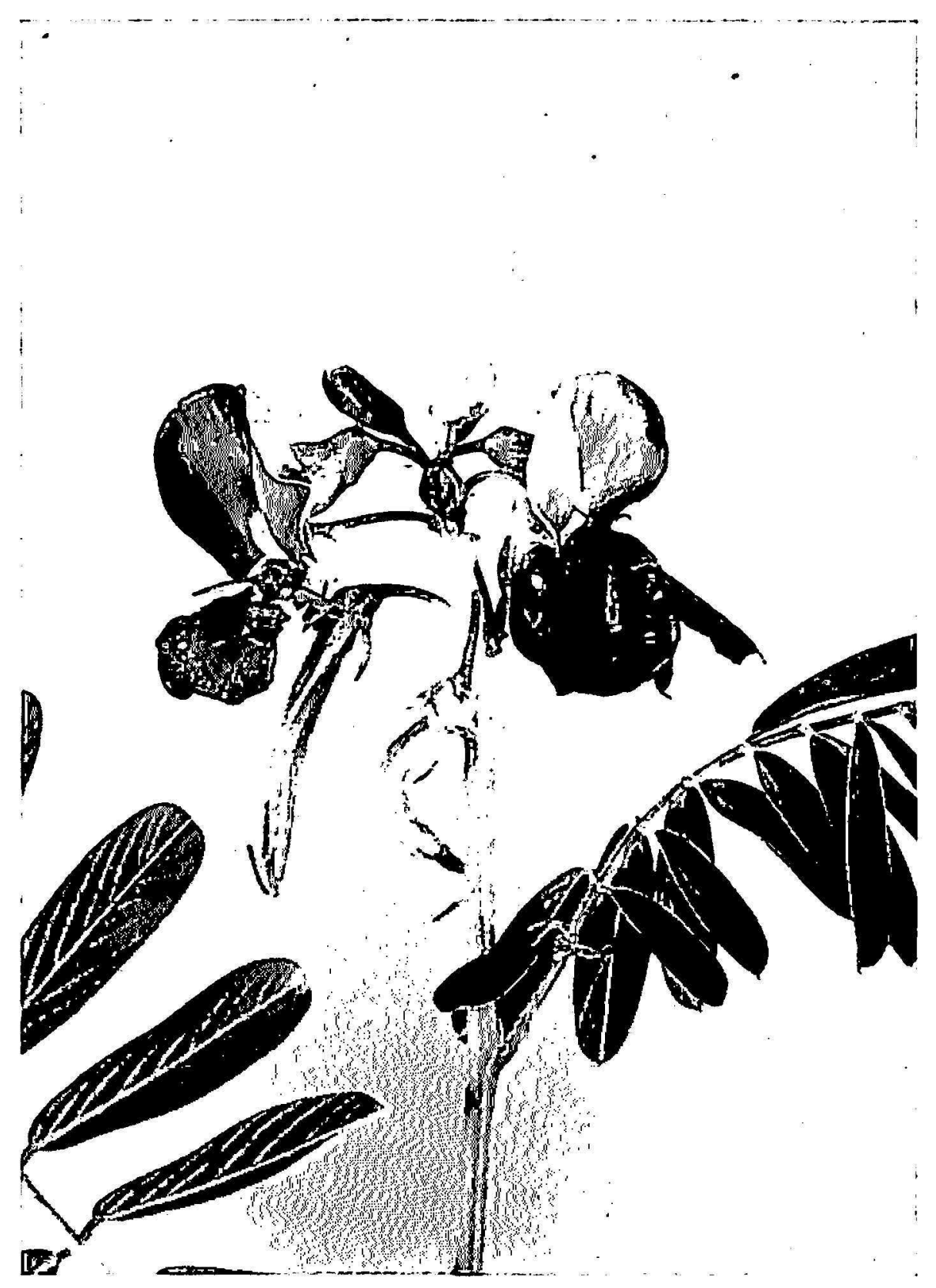

Frg. 1.-Honey bee and carpenter bee visiting $T$. vogelii flowers.

\section{METHODS AND PROCEDURES}

The natural self-pollination characteristics of $T$. vogelii made it necessary to develop procedures for making emasculations and controlled crosspollinations. Emasculations are made routinely in the afternoon and pollinations are made during the morning. Before emasculation all open flowers or pods are removed from a raceme. Buds expected to open in 2 days are 


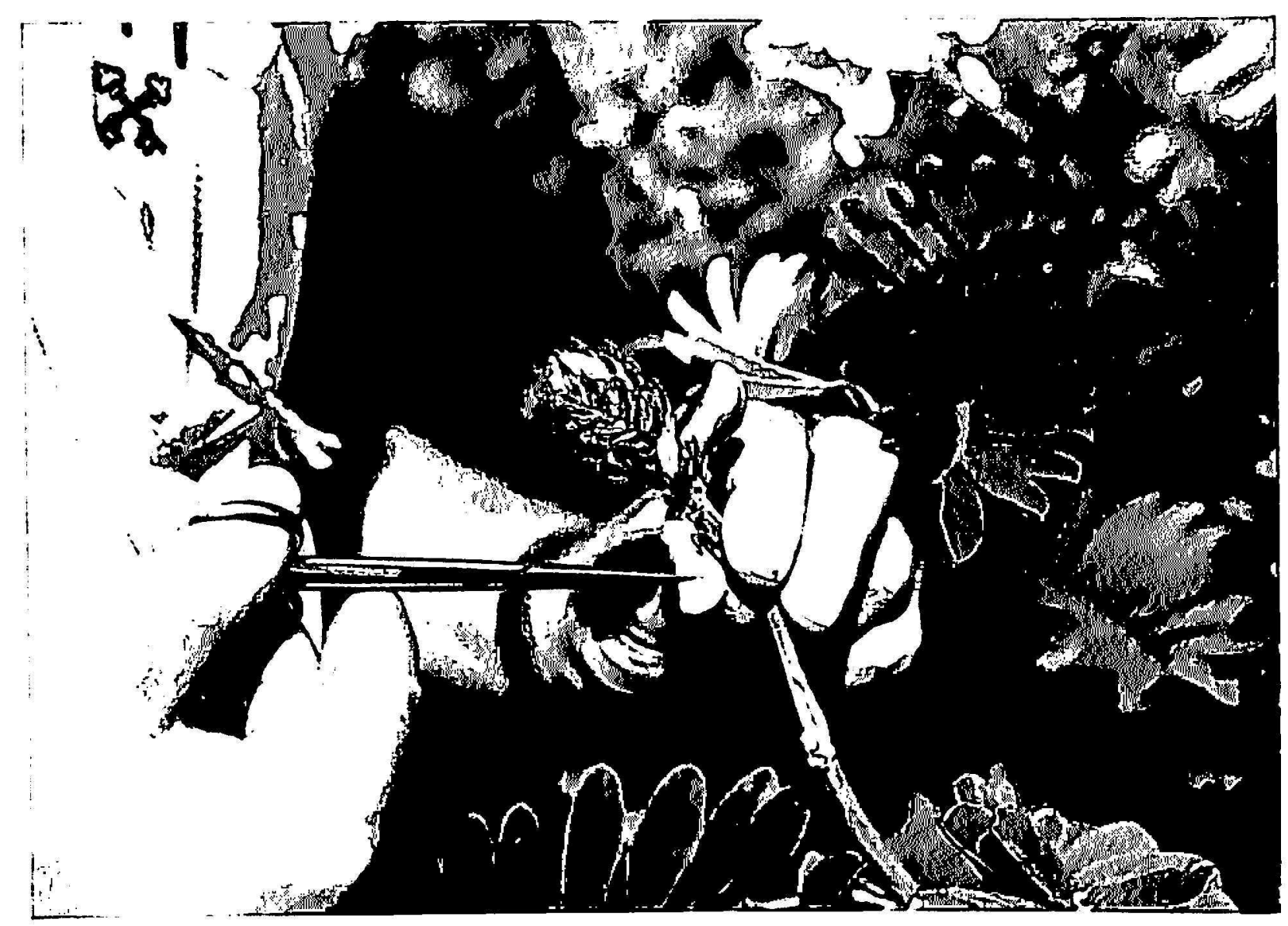

FIG. 2.-Cutting T. vogelii floral bud during first st ep of floral emasculation.

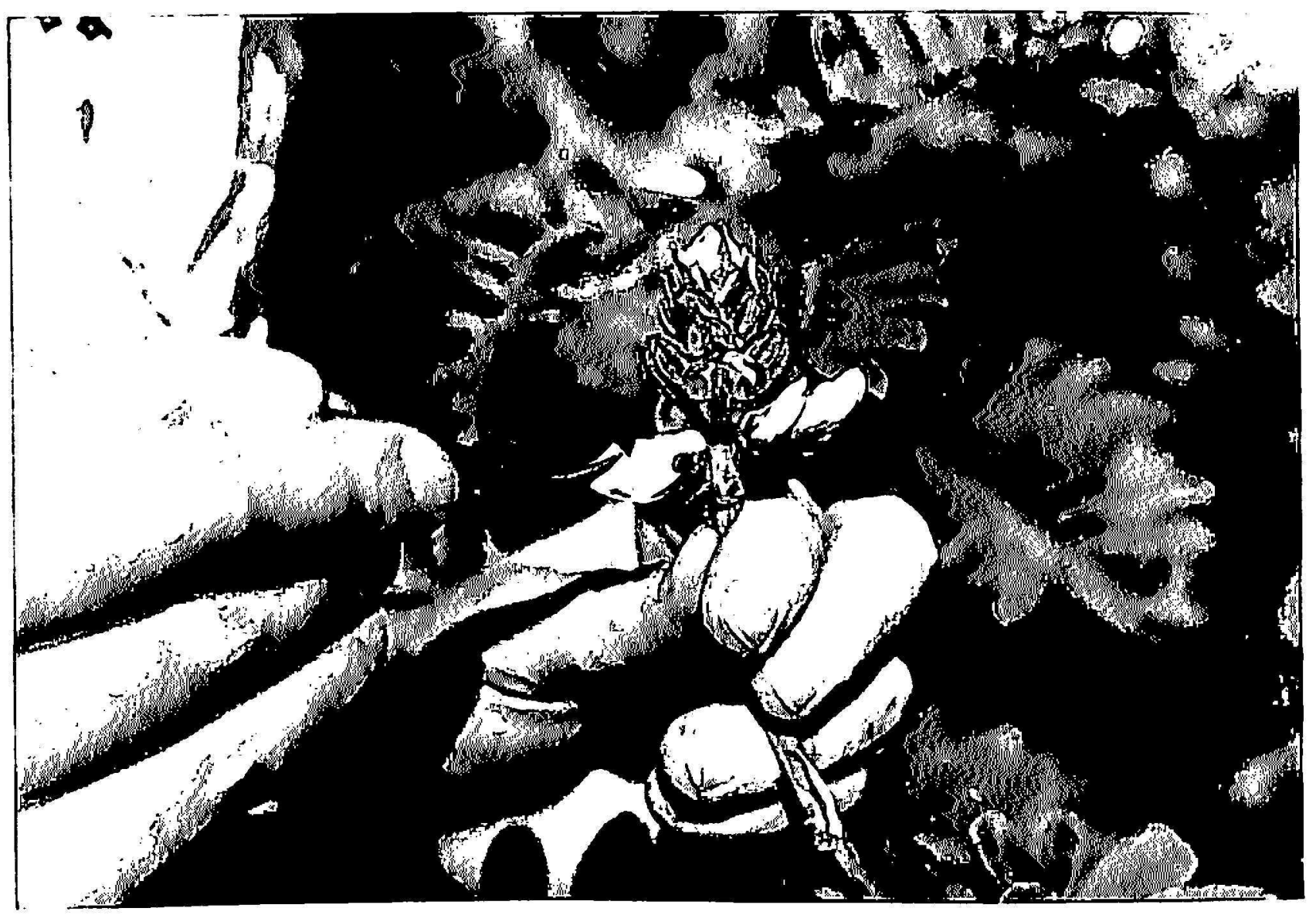

Fuci. 3.- (irasping bud of ' $T$ '. rogelii floret with forceps prior 1 o removing pet als during flural emasculation. 


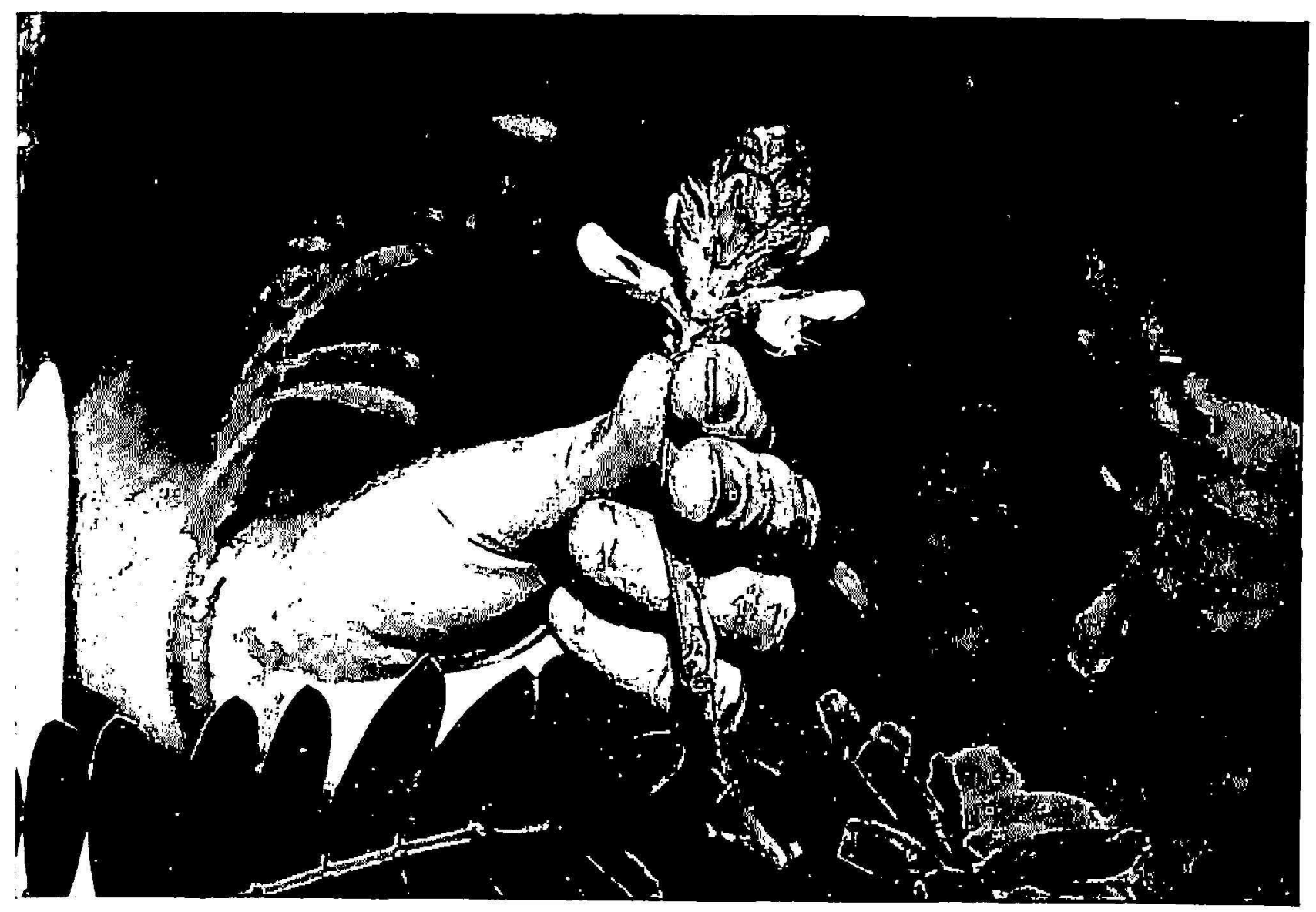

FIG. 4.-Bud of T. vogelii floret after emasculation.

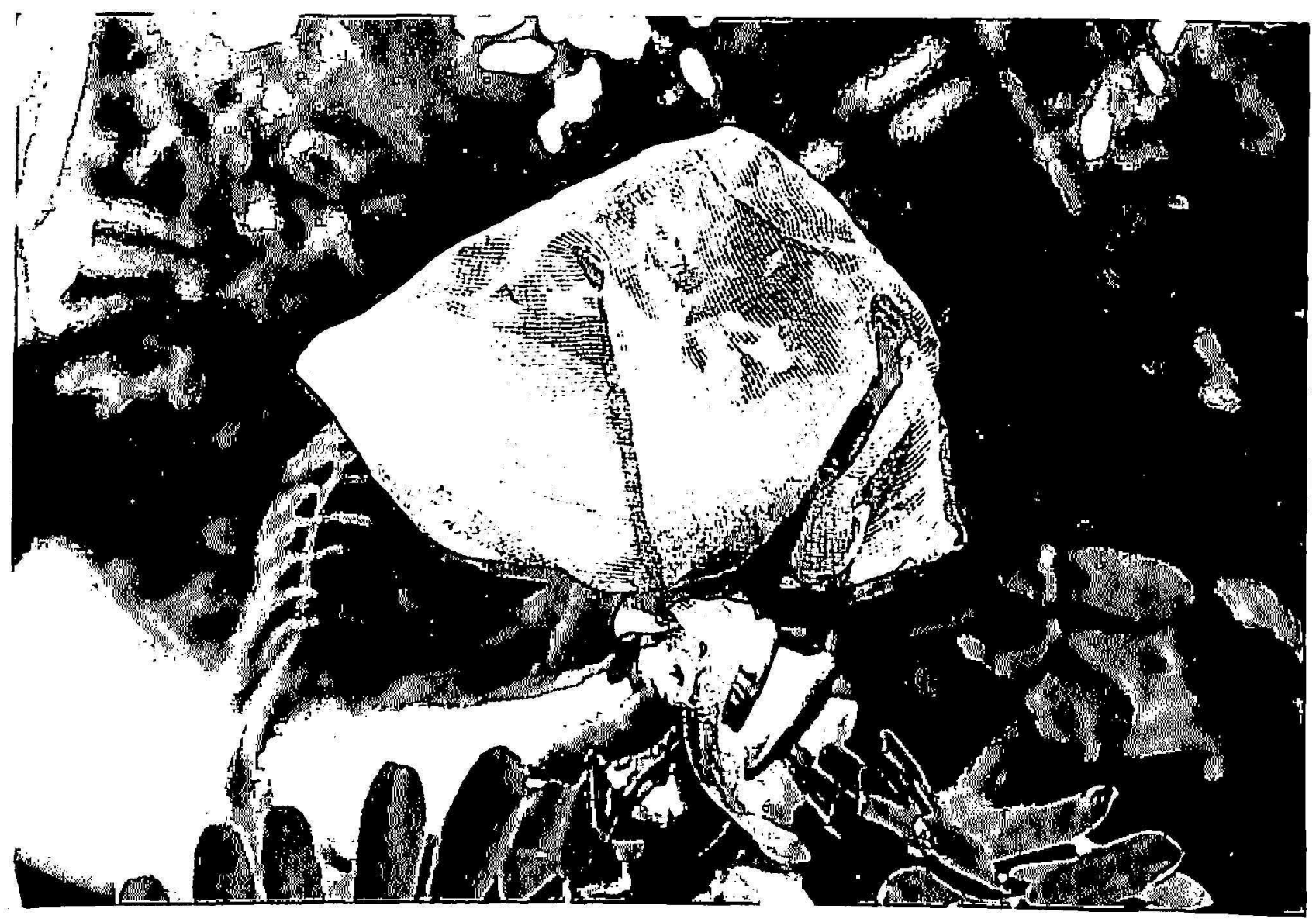

Fig. 5.- Nylon netting covering emasculated florets of $T$. vogelii. 
selected for emasculation. Buds which will open the following day are not used because the anthers often are already starting to dehisce or will dehisce during emasculation. The selected buds are partially cut with scissors (figure 2). The tip of the cut bud is grasped with a forceps (figure 3) and pulled off. This removes the petals and exposes the stigma (figure 4). Usually most of the anthers are removed when the petals are pulled off. Remaining anthers are removed with the forceps. Usually 4-6 florets can be emascu-

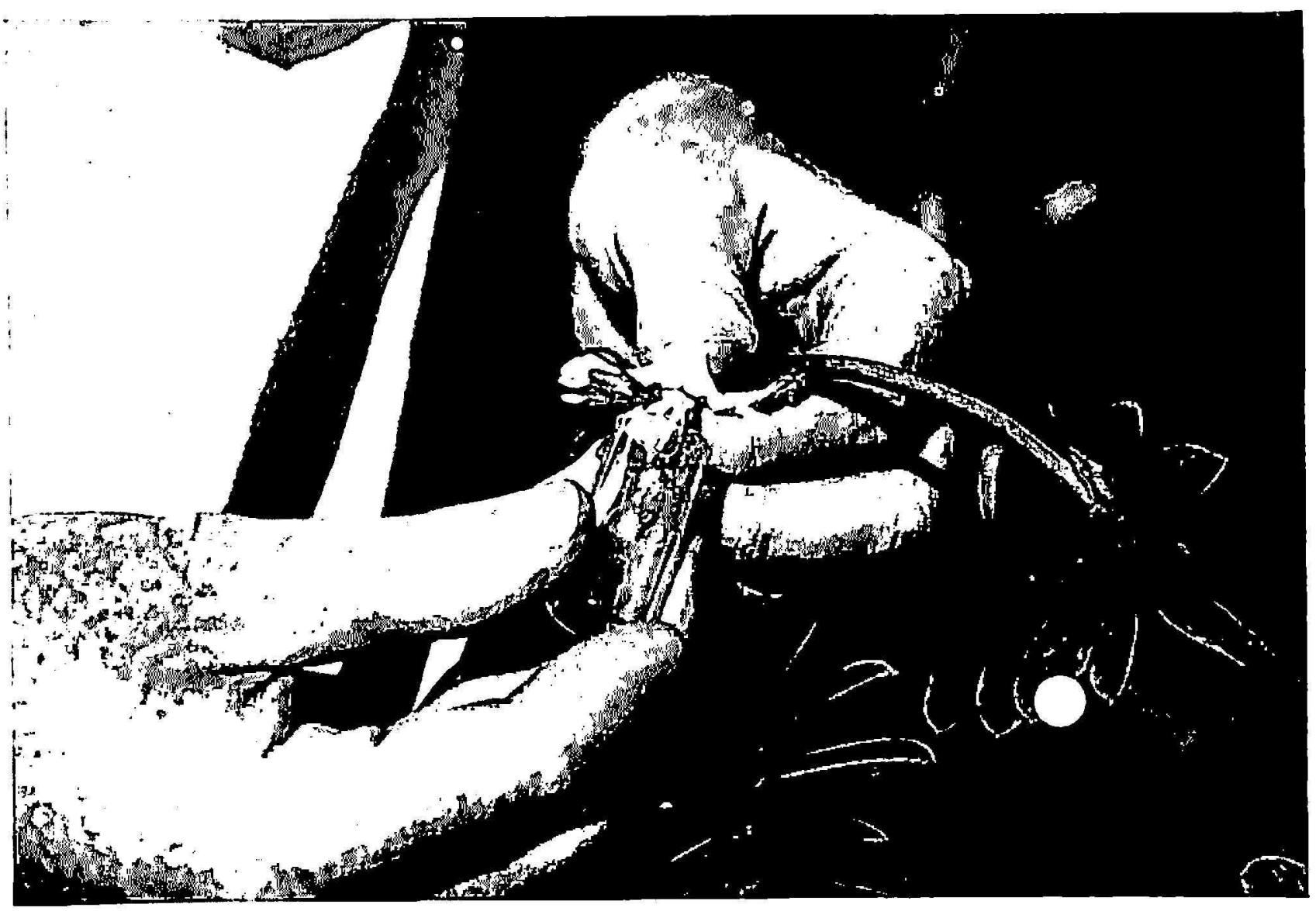

FIG. 6.-Pollinating emasculated florets of $T$. vogelii by rubbing stigmas in vial of pollen.

lated on a raceme at any one time. The emasculated florets are covered with a piece of nylon netting (figure 5) until pollination.

Two days after emasculation pollen is collected by tearing open several unfolding buds or newly opened flowers and rubbing the dehiscing anthers into a small glass vial. The time of another dehiscence often varies greatly among breeding lines. Pollen is shed in some lines very early in the morning when the warm sun first strikes the florets, whereas other lines do not shed pollen until nearly midday. The collected pollen is carried to the emasculated florets and the stigmas inserted into the vial and rubbed against the side of the vial (figure 6). This simultaneously ruptures the stigmatic 
membrane and covers the stigma with pollen. This is repeated until all emasculated florets on the raceme have been pollinated. The raceme is tagged and covered with nylon netting. The netting is left on for only a few days until the pods begin to enlarge. The netting then can be taken off and the remaining flowers and buds cut off or new emasculations made on the same raceme. It is best not to leave the raceme covered any longer than necessary because the covered racemes do not dry as quickly as normal, therefore making them more prone to foliar blights (Ruppel et al. (8), and Theis et al. (4).

One man can emasculate and cover approximately 100 to 200 florets in an afternoon and pollinate the same number of florets during a morning. These procedures have proven to be fast and effective.

\section{SUMMARY}

$T$. vogelii was observed to be primarily a self-pollinated species, but one that requires an insect to trip the flowers. The carpenter bee, $X$. brasilianorum, was reported to be the primary insect pollinator of $T$. vogelii in Puerto Rico. Emasculation and controlled cross-pollination procedures for $T$. vogelii were developed and described graphically.

\section{RESUMEN}

Se observó que la T. vogelii es una especie que es primordialmente autopolinizable, aunque no obstante, requiere que un insecto se pose y holle las flores para que tenga lugar la polinización. Se informó que el cigarrón, $X$. brasilianorum, es el principal insecto polinizador de la T. vogelii en Puerto Rico. Se desarrollaron y describieron gráficamente los procedimientos para la emasculaicón y polinización cruzada y regulada en la $T$. vogelii.

\section{LITERATURE CITED}

1. Irvine, J. E., and Freyre, R. H., Varietal differences in the rotenoid content of Tephrosia vogelii, Agron. J. 61: 664-65, 1959.

2. Barnes, D. K., Freyre, R. H. Higgins, J. J. and Martin, J. A., Rotenoid content and growth characteristics of T'ephrosia vogelii as affected by latitude and within-row spacing, Crop Sci. 7: 93-5, 1967.

3. Ruppel, E. G., Barnes, D. K. and Santiago, Alma, Potential of three Rhizoclonia species to incite foliar blight and damping-off on Tephrosia vogelii in Puerto Rico, Phylopalhology 65: 612-14, 1965.

4. Theis, T., Freyre, R. H. and Kennard, W. C., Pellicularia filamentosa on Tephrosia vogelii and Cajanus indicus in Puerto Rico, FAO Plant Prolection Bull. 5: 15960, 1957. 